\title{
Frequency and Cause of Parkinson's Disease
}

\author{
A.H. Rajput
}

\begin{abstract}
Parkinson syndrome (PS) is a common disorder in the North American population. The annual incidence rate is $20.5 / 100,000$ population and the mean survival after onset is approximately 12.3 years. The estimated prevalence rate is about $300 / 100,000$ population. The incidence and prevalence rates rise with advancing age. Both the widespread use of levodopa and the improved health care in general have increased the longevity in PS. The survival in PS from the time of the first clinic visit is still significantly shorter when compared with the regional age and sex matched population. The cause of IPD may be related to some environmental factor(s) - most likely a toxin. Genetic factors are not the cause but in some families, may predispose to IPD.
\end{abstract}

RÉSUMÉ: Fréquence et cause de la maladie de Parkinson. Le syndrome de Parkinson (SP) est une affection fréquente dans la population nord-américaine. L'incidence annuelle est de 20.5/100,000 de population et la survie moyenne est d'environ 12.3 ans après le début de la maladie. La prévalence est estimée à environ 300/100,000 de population. L'incidence et la prévalence augmentent avec l'âge. L'utilisation courante de la lévodopa et l'amélioration des soins de santé en général ont augmenté la longévité dans le SP. La survie dans le SP, à partir du moment de la première visite médicale, est encore significativement plus courte comparée à celle de la population régionale, appariée pour l'âge et le sexe. La cause de la maladie de Parkinson idiopathique (MPI) pourrait être reliée à un ou des facteurs environnementaux - très probablement une toxine. Des facteurs génétiques n'en sont pas la cause mais, dans centaines familles pourraient prédisposer à la MPI.

Can. J. Neurol. Sci. 1992: 19: 103-107

Parkinson Syndrome (PS) is not one, but a collection of disorders which share common clinical features - tremor, bradykinesia and rigidity. The most common variation is the Lewy body (LB) disease ${ }^{1.2}$ but the pathological basis cannot be ascertained in all cases during life ${ }^{3}$ on the basis of clinical evaluation and the majority of PS respond to levodopa. ${ }^{4}$ Consideration of the incidence and prevalence rates should therefore include all varieties of PS.

The PS is a ubiquitous disorder reported in every race and every region of the world. In a recent survey, ${ }^{5}$ PS ranked tenth among the disorders requiring neurological services in Saskatchewan. In several carefully conducted, communitybased studies there is no reported difference in the incidence rates between males and females. ${ }^{16-9}$

\section{Onset Age}

The motor onset of PS in most patients is after age 40 years. Possible change in the age at onset due to natural events has been debated for several decades. ${ }^{8.10 .11}$ In a clinic-based study, $10 \%$ of the "primary" parkinsonism cases seen between 1949 and 1964, the onset was prior to age 40 years. ${ }^{12}$ More recently, Teravanian et al. ${ }^{.1}$ reported the onset under age 40 years in $8 \%$ of patients. In most other studies between $4 \%$ and $7 \%$ of the cases had onset before the age of 40 years. The age-specific incidence rises with advancing age. ${ }^{1.7 .13}$ The largest proportion of the reported cases, however, have motor onset during the late 6 th or 7th decade of life. ${ }^{12.14,15}$ In our series of 934 PS patients seen during 22 years (1968-1990), the mean age at onset was 51.5 years. ${ }^{15}$

The diagnosis of PS in elderly subjects is sometimes difficult as it may be mistaken as another illness or other illnesses may mask the PS features. We noted that $40 \%$ of the PS cases in 65 years and older hospitalized patients were not diagnosed by the family physician. ${ }^{16}$ Schoenberg et al. ${ }^{6}$ in a community survey noted a similar percentage of underdiagnosis of PS.

\section{Incidence}

The reported annual incidence rates vary from 5 to $24 / 100,000 .^{14}$ There are several reasons for such wide variations. The difference in the life expectancy of the regional population, the type of PS included and the completeness of case finding are the main considerations. Rochester, Minnesota is the only source of several sequential incidence studies of PS since the 1930 's. ${ }^{1}{ }^{10.13,17}$ The most recent reported annual incidence of PS in the Rochester population is $20.5 / 100,000$. $^{\prime}$ That is not significantly different from the previous reported incidence rate. ${ }^{13}$

Postencephalitis parkinsonism (PEP) which was once a common PS variant ${ }^{12.13,17.18}$ came to a natural conclusion beginning around 1960.1.18.19 However there has been no decline in the incidence of PS to coincide with that which indicates that either the other variants of PS are now emerging more frequently or are being diagnosed more often. ${ }^{1.13 .17}$ Completeness of case ascertainment is essential for the incidence studies of PS. The easier neurologist access and increased diagnostic accuracy in 
recent years undoubtedly accounts for some increase in case findings. The other reason is that the population at risk of PS has been steadily increasing over the past several decades. The incidence figures from Rochester, Minnesota, though among the best available, are regarded by Kurland ${ }^{17}$ as "minimal" because it is not possible to identify all PS patients.

\section{Race and Parkinsonism}

Although some reports indicate that blacks have a lower incidence of PS than whites, ${ }^{20-22}$ in a carefully conducted study of a bi-racial Mississippi community which had an equal number of black and white residents, Schoenberg et al. ${ }^{6}$ found no racial difference. In a separate study, Schoenberg et al., ${ }^{23}$ noted that the blacks in the U.S. had nearly 5 times the prevalence rate of Parkinson's disease compared to the blacks in Nigeria. Taken together these studies indicate that blacks do not have a natural immunity to developing PS.

\section{Mortality}

Mortality in PS has been a topic of special interest since the 1960's. It was anticipated that on levodopa therapy the survival would increase. That hypothesis has, however, been difficult to verify. The two major problems have been: the diversity of inclusion criteria and the differences in the analysis and reporting of the mortality rates utilized by different workers.

The most commonly cited mortality rate during the prelevodopa era is that reported by Hoehn and Yahr in 1967.12 They noted that the observed to expected mortality ratio in primary parkinsonism was 2.9:1. They included the PS cases seen at a large neurological institution between 1949 and 1964 but did not analyze the impact of treatment on the survival. Nobrega et al. ${ }^{13}$ who studied PS patients in Rochester, Minnesota between 1935-1966 prior to levodopa usage, noted that the mortality ratio was 1.6 times higher than expected in the general population. The marked difference in these two reports indicates that a comparison of the mortality rates in the contemporary PS cases with any of the studies conducted prior to widespread use of L-Dopa is problematic.

Identifying PS cases that may be comparable to those classified as "primary" parkinsonism by Hoehn and Yahr ${ }^{12}$ is not possible.' Similarly we cannot recognize or critically evaluate those prelevodopa era cases that would be comparable to the $50 \%^{1}$ to $72 \%{ }^{6}$ cases that may now be treated with L-Dopa. Limiting the survival considerations to only the L-Dopa treated cases therefore will not provide accurate information on survival in the PS cases today. The observed to expected mortality ratio in the LDopa treated cases ranges from $0.97^{24}$ to $1.85^{25}$ in different studies.

Another source of error has been the index date when the PS cases are assigned for comparison with the general population. Almost no patient is seen and diagnosed on the day the parkinsonian features emerge. There is a variable lag - often years between the onset and diagnosis. During that interval, some PS cases would have died. Retrospectively, assigning the comparison of those surviving patients in whom the diagnosis was made with the general population from the date of onset of PS assumes no deaths in PS cases and thus introduces a bias favouring the patients.

Given the unsurmountable difficulties in conducting an ideal study to answer the question of survival changes due to widespread use of L-Dopa, the best information may be obtained from a study of all PS patients compared with the regional population cohort.

Hoehn and Yahr in $1967^{12}$ reported 10.8 years mean life expectancy in all PS and 9.4 years in the "primary" parkinsonism. A similar figure ( 10 year survival) was noted by Kurland in $1958 .{ }^{17}$ Most workers have used an average 10 year survival as the benchmark figure ${ }^{17}$ for the period before the widespread use of L-Dopa.

The mean survival in all PS cases regardless of the treatment - in our cases over the 22 years - was 12.3 years. These included many severely advanced patients at the time of initial evaluation during the late 60's and early 70's. Analysis of more recent cases may produce different results. When compared with 10.8 years survival reported by Hoehn and Yahr in $1967^{12}$ at a large neurological hospital, the life expectancy in PS has increased in the last two decades. Hoehn and Yahr ${ }^{12}$ series included a larger proportion of PEP cases than in our study. The PEP patients have an early age at onset and longer survival ${ }^{12}$ compared to the other PS variants. When we take that into consideration, the evidence for an increased survival in the PS population is even more convincing. The reasons for the improved survival and in particular, the role of LD therapy, remain to be clarified. Lilienfeld et al. ${ }^{26,27}$ noted that a decline in PS death rate among those under age 70 years began in the mid 1960's - prior to the widespread use of L-Dopa. The increased survival in PS may therefore be due to combination of better management of other illnesses as well as the widespread use of L-Dopa.

Our clinic-based population resembles the age at onset and severity profiles in a large population survey of PS. ${ }^{9}$ The survival in all our PS cases, when measured from the first assessment at the Movement Disorder Clinic, was significantly reduced compared to the regional population. ${ }^{15}$ Thus the survival in PS is now longer than in the past but it remains shorter than expected.

\section{Prevalence of Parkinsonism}

A number of methods have been used to determine the prevalence rate of PS, the most convenient being the identification of the diagnosis on death certificates. That is, however, the least accurate method. ${ }^{7}$ Kurland ${ }^{17}$ noted that in only $46 \%$ of the known cases, the PS diagnosis was listed as the primary cause of death and Chandra et al. ${ }^{28}$ found only $25 \%$ of PS cases were identified on the death certificates.

Assessment of LD consumption in a community has been used to extrapolate the number of PS patients in the population. ${ }^{29}$ That is an indirect and an inaccurate method if we consider that between $28 \%$ and $50 \%$ of the PS patients in a community may not be treated with levodopa. ${ }^{1,6}$

The two most reliable methods are the survey of all cases in a community and an estimation of prevalence rate based on incidence and survival rates.

The ideal method for determining prevalence rate of PS is to identify all the patients in a large and representative sample of general population. This approach is time and labour intensive and in practice has its own limitations. Schoenberg et al. ${ }^{6}$ in a door-to-door survey of Copiah County, Mississippi could not evaluate $3 \%$ of the population and $15 \%$ of the suspected cases did not permit final confirmation of the diagnosis. This survey ${ }^{6}$ 
was limited to 40 years and older individuals, thus excluding identification of approximately $5 \%$ of the PS cases. Bharucha et al..$^{30}$ also failed to interview $5.4 \%$ of the households and $17 \%$ of suspected cases refused final evaluation.

Another reliable method to determine the prevalence rate is to multiply the best available incidence rates with the best available information on mean life expectancy after onset of PS.

The latest incidence of PS reported in the Rochester, Minnesota population is $20.5 / 100,000$. $^{\prime}$ Assuming that there is an underdiagnosis in the elderly, the actual incidence rate may well be close to $27 / 100,000$. In our large study of all inclusive PS cases in Saskatoon, the mean survival was 12.3 years. If we do not make allowance for the underdiagnosis, the prevalence rate would be $252 / 100,000$. On the other hand, if we take the underdiagnosis into consideration, the prevalence rate would be $333 / 100,000$ - a rate surprisingly close to $328 / 100,000$ reported by Bharucha et al..$^{31}$ in a Parsi community in India. The available data do not permit more precise estimation. The reported prevalence rates in the past have varied considerably. ${ }^{14}$ Kurland ${ }^{17}$ considered the reported rates underestimates, as all patients may not be recognized and included for a variety of reasons. In my opinion, the PS prevalence rate today in Canada is close to $300 / 100,000$.

The prevalence rate of PS increases with age. Schoenberg et al. ${ }^{6}$ noted a prevalence ratio of $128 / 100,000$ in population between age 40-64 years and a seven-fold higher $(958 / 100,000)$ ratio in those over age 75 years. A similar pattern has been reported in several other studies from different parts of the world..$^{30.32}$ It is reasonable to predict that in the absence of major change in the incidence rate, the prevalence rate of PS will rise in the future as the proportion of the elderly is rising. In 1958 the lifetime risk for parkinsonism was estimated at $2.5 \%$ by Kurland. ${ }^{17}$ Because of the increasing life expectancy, the risk may need reassessment.

\section{Cause of Parkinson's Disease}

The cause of Parkinson syndrome is difficult to address as it is not one, but a collection of disorders. In several variants of PS such as PEP, MPTP-induced parkinsonism, PS due to carbon monoxide poisoning and drug-induced parkinsonism, etc., the cause is well known and the same anatomical site may be damaged by different insults producing similar clinical picture. At this stage in our understanding of PS, it is therefore prudent to restrict the etiological consideration to a reasonably homogeneous entity.

The most common histological abnormality in PS is that characterized by loss of substantial nigra (SN) neurons and Lewy body (LB) inclusions. ${ }^{33,34}$ This subgroup accounts for approximately $80 \%$ of the cases in most large series and is usually known as idiopathic Parkinson's disease (IPD) or Parkinson's disease. ${ }^{34}$

Since IPD is a disorder of later age, the significance of normal or accelerated aging process in the etiology needs serious consideration. Alternatively, the age related SN cell loss may predispose or add to the effects of another insult. ${ }^{35}$ According to two reports, ${ }^{36,37}$ the normal age-related $\mathrm{SN}$ neuronal loss alone is not sufficient to produce parkinsonian features even if an individual were to survive more than 100 years. We have recently noted that the pattern of striatal dopamine loss in old age is sig- nificantly different from that in IPD. ${ }^{38}$ Idiopathic Parkinson $\mathrm{s}$ disease is therefore a pathological entity.

There are two main schools of thought on the cause of the pathological SN neuronal loss which leads to parkinsonian manifestations. The first possibility is that it is a genetically linked disorder. Alternatively IPD is an acquired disorder consequent to environmental factor(s).

The genetic basis of parkinsonism has been recently discussed in detail by Golbe. ${ }^{39}$ While there is some anecdototal information on the genetic predisposition to IPD, only two studies of familial cases deserve serious consideration. Muenter et al. ${ }^{40}$ reported one family with akinetic rigid parkinsonism and severe dementia. The symptoms in these patients started at an early age resulting in death after $4-17$ years. These patients had pathological features of IPD as well as limbic system pathology - which is not a characteristic of IPD. Golbe et al. ${ }^{41}$ reported 41 patients, including one autopsy case, with Lewy body pathology in a large kindred. The genetic pattern was consistent with dominant mode of transmission. These patients had an unusually early onset age (mean 46 years) and rapid progression resulting in death on the average in 9.7 years. These two kindred, therefore, represent highly malignant forms of the disease compared to the commonly seen IPD cases. My interpretation of these two kindred is that they are examples of an increased vulnerability to the environmental factor(s) which cause IPD.

There are 3 major studies of twins. ${ }^{42-44}$ Neither detected the concordance rate of IPD significantly higher than expected in the general population. Some of these studies are being re-evaluated now. In view of the well-conducted previous studies. when further details of the new efforts become available, they should be carefully scrutinized. ${ }^{45}$

The observations by Schoenberg et al., ${ }^{6}$ that blacks in the U.S. have the same prevalence rate as whites, but U.S. blacks have significantly higher prevalence rate than African blacks, ${ }^{2 .}$ further indicate against the genetic hypothesis. These and several other studies dealing with mortality and racial patterns indicate that some environmental factor(s) is the cause of IPD. $8.27 .46-52$

There are several known causes of PS but none has been clearly linked with the Lewy body disease (IPD). Methyl phenyl tetrahydropyridine (MPTP) is well known to produce Parkinson syndrome in man and in animals. ${ }^{53}$ The major anatomical site of lesion is the SN. Studies of old monkeys treated with MPTP show loss of the $\mathrm{SN}$ and the locus ceruleus neurons and inclusion resembling Lewy body. ${ }^{54}$ Whether a naturally-occurring MPTP-like substance or some other toxin which is widely disseminated in the world produces Parkinson's disease remains to be established. ${ }^{8}$ Our search for MPTP in the drinking water consumed by patients has been unrewarding.

Several environmental agents including virus infections, metal toxicity, herbicides and pesticides have been considered but not clearly linked with IPD. ${ }^{55}$ Hertzman et al. ${ }^{46}$ have recently reported that working in orchards increased the risk of IPD but this needs confirmation by others.

The natural history of IPD indicates that whatever the cause, if the disease process is once triggered, it would perpetuate. Calne and Lees ${ }^{56}$ noted late progression even in the PEP cases. It is possible that a toxin is incorporated within the SN neuron producing borderline metabolic compromise and slow death. Alternatively, once the pathology is triggered in some cells, it 
becomes a self-perpetuating process involving other cells consequent to metabolic by-products of dopamine breakdown. ${ }^{57.58}$

Because the disease manifests around age 60 years and there is an unknown but long preclinical interval, identification of the environmental etiology is very difficult. We investigated IPD in under 40 year age onset cases and noted a strong rural predisposition. ${ }^{49}$ Others in North America ${ }^{40.50 .51}$ and in Europe ${ }^{48}$ have made similar observations. An alternative explanation is that the urban residents are immune to the environmental factor(s) that produce IPD.

Eldridge et al. ${ }^{59}$ suggested that those predisposed to IPD are born with fewer SN cells. That is a difficult hypothesis to verify. Mattock et al. ${ }^{60}$ postulated that an in-utero influenza virus exposure may result in IPD at a later age but this could not be substantiated by Ebermier et al. ${ }^{61}$ The protective effect of smoking against IPD has been a source of an unnecessarily prolonged debate when we consider that this has not been confirmed by several meticulously conducted studies. ${ }^{8}$

In order to attain an insight into the cause of IPD, attempts have been made to identify other disorders that precede or coexist in IPD cases. In one study of IPD patients whose health records for the 40 years preceding the motor onset of PS were available, 89 different disorders and smoking habits were compared with the control population from the same community. ${ }^{62}$ Only the prior diagnoses of psychoneurosis and psychosomatic illnesses were significantly more common among the patients than in the controls. ${ }^{62}$ Since the cause of psychoneurosis and psychosomatic illnesses each is unknown, these observations are not helpful in identifying the cause of IPD. Dementia evolves more often after the onset of the IPD in the cases than in the controls. ${ }^{62-64}$ The significance of that to the etiology of IPD remains to be determined.

\section{REFERENCES}

1. Rajput AH, Offord KP, Beard CM, et al. Epidemiology of parkinsonism: incidence, classification, and mortality. Ann Neurol 1984; 16: 278-282.

2. Jellinger K. Pallidal, pallidonigral and pallidoluysionigral degenerations including association with thalamic and dentate degenerations. In: Vinken PJ, Bruyn GW, Klawans HL, eds. Handbook of Clinical Neurology; Extrapyramidal Disorders. 49th ed. New York: Elsevier Science Publishing Co. Inc. 1986: 445-463.

3. Rajput AH, Rozdilsky B, Rajput Alex H. Accuracy of clinical diagnosis in parkinsonism - a prospective study. Can J Neurol Sci 1991; 18: 275-278.

4. Rajput AH, Rozdilsky B, Rajput Alex, Ang L. Levodopa efficacy and pathological basis of Parkinson syndrome. Clin Neuropharmacol 1990; 13 (6): 553-558.

5. Rajput AH, Uitti RJ, Rajput Alex H. Neurological disorders and services in Saskatchewan - a report based on provincial health care records. Neuroepidemiology 1988; 7: 145-151.

6. Schoenberg BS, Anderson DW, Haerer AF. Prevalence of Parkinson's disease in the biracial population of Copiah County, Mississippi. Neurology 1985; 35 (6): $841-845$.

7. Schoenberg BS. Environmental risk factors for Parkinson's disease: the epidemiologic evidence. Can J Neurol Sci 1987; 14: 407413.

8. Tanner CM, Langston JW. Do environmental toxins cause Parkinson's disease? A critical review. Neurology 1990; 40 (Suppl 3): 17-30.

9. Marttila RJ, Rinne UK. Dementia in Parkinson's disease. Acta Neurol Scand 1976; 54: 431-441.

10. Kurland LT, Hauser WA, Okazaki H, Nobrega FT. Epidemiologic studies of parkinsonism with special reference to the cohort hypothesis. In: Proceedings of Third Symposium on Parkinsonism. Edinburgh: E \& S Livingstone, Lid., 1969: 12-16.

11. Teravainen H, Forgach L, Heitanan $M$, et al. The age of onset of Parkinson's disease: etiological implications. Can J Neurol Sci 1986; 13: 317-319.

12. Hoehn MM, Yahr MD. Parkinsonism: onset, progression, and mortality. Neurology 1967; 17: 427-442.

13. Nobrega FT, Glattre E, Kurland LT, Okazaki H. Comments on the epidemiology of parkinsonism including prevalence and incidence statistics for Rochester, Minnesota, 1935-1966. In: Barbeau A, Brunette JR, eds. Progress in Neurogenetics. Amsterdam: Excerpta Medica, 1967: 474-485.

14. Marttila RJ. Epidemiology. In: Koller WC, ed. Handbook of Parkinson's Disease. New York: Marcel Dekker Inc., 1987: 3550 .

15. Uitti RJ, Rajput AH, Offord KP. Parkinsonism survival in the Levodopa era. Neurology 1991; 41 (suppl 1): 190.

16. Bennett VL, Rajput AH, Bonat JR, et al. Underdiagnosis of Parkinson's disease in the elderly. Trans 2nd Annual Symposium on Parkinson's disease 1988: (abstract).

17. Kurtland LT. Epidemiology: incidence, geographic distribution and genetic considerations. $I n$ : Fields WS, ed. Pathogenesis and Treatment of Parkinsonism. Springfield, Illinois: Thomas, 1958: 5-43.

18. Krusz JC, Koller WC, Ziegler DK. Historical review: abnormal movements associated with epidemic encephalitis lethargica. Mov Disord 1987; 3 (3): 137-141

19. Duvoisin RC, Yahr MD. Encephalitis and parkinsonism. Arch Neurol 1965; 12: 227-239.

20. Kessler II. Epidemiology study of Parkinson's disease. Am J Epidemiol 1972; 96: 242-254.

21. Paddison RM, Griffith RP. Occurrence of Parkinson's disease in black patients at Charity Hospital in New Orleans. Neurology 1974; 24: 688 .

22. Rosati G, Graniere E, Pinna L, et al. The risk of Parkinson's disease in Mediterranean people. Neurology 1980; 32: 250-255.

23. Schoenberg BS, Osuntokun BO, Adejua AOG, et al. Comparison of the prevalence of Parkinson's disease in black populations in the rural United States and in rural Nigeria: door-to-door community studies. Neurology 1988; 38: 645-646.

24. Diamond SG, Markham CH. Present mortality in Parkinson's disease: the ratio of expected to observed deaths with a method to calculate expected deaths. J Neural Transm 1976; 38: 259-269.

25. Marttila RJ, Rinne UK, Siirtola T, Sonninen V. Mortality of patients with Parkinson's disease treated with levodopa. J Neurol 1977; 216: 147-153.

26. Lilienfeld DE, Chan E, Ehland J, et al. Two decades of increasing mortality from Parkinson's disease among the U.S. elderly. Arch Neurol 1990; 47: 731-734.

27. Lilienfeld DE, Sekkor D, Simpson S, et al. Parkinsonism death rates by race, sex and geography: a 1980 's update. Neuroepidemiology 1990; 9: 243-247.

28. Chandra V, Bharucha NE, Schoenberg BS. Mortality data for the U.S. for deaths due to and related to twenty neurologic diseases. Neuroepidemiology 1984; 3: 149-168.

29. de Pedro J, Rosenqvist U. Tracers for paralysis agitans in epidemiological research. Neuroepidemiology 1984; 3: 82-96.

30. Bharucha NE, Bharucha EP, Bharucha AE, et al. Prevalence of Parkinson's disease in the Parsi Community of Bombay, India. Arch Neurol 1988; 45: 1321-1323.

31. Mutch WJ, Dingwall-Fordyce I, Downie AW. Parkinson's disease in a Scottish city. BMJ 1986; 292: 534-536.

32. Marttila RJ, Rinne UK. Epidemiology of Parkinson's disease in Finland. Acta Neurol Scand 1976; 53: 81-102.

33. Jellinger $K$. The pathology of parkinsonism. In: Marsden CD, Fahn S, eds. Movement Disorders 2. London: Butterworths and Co., 1987: 124-165.

34. Duvoisin R, Golbe Ll. Toward a definition of Parkinson's disease. Neurology 1989; 39: 746.

35. Calne DB, Langston JW. Aetiology of Parkinson's disease. Lancet 1983; 2 : 1457-1459.

36. McGeer PL, McGeer EG, Suzuki JS. Aging and extrapyramidal function. Arch Neurol 1977; 34: 33-35. 
37. Thiessen B, Rajput AH, Laverty W, Desai HB. Age, environments and the number of substantia nigra neurons. In: Streifler MB, Korczyn AD, Melamed E, Youdim MBH, eds. Advances in Neurology. New York: Raven Press, 1990: 201-206.

38. Kish SJ, Shannak K, Rajput A. Aging produces a specific pattern of striatal dopamine loss: implications for the etiology of idiopathic Parkinson's disease. J Neurochem 1991 (in press).

39. Golbe LI. The genetics of Parkinson's disease: a reconsideration. Neurology 1990; 40 (Suppl. 3): 7-14.

40. Muenter MD, Howard FM, Okazaki H, et al. A familial parkinsondementia syndrome. Neurology 1986; 36 (Suppl 1): 115.

41. Golbe LI, Di lorio G, Bonavita V. A large kindred with autosomal dominant Parkinson's disease. Ann Neurol 1990; 27: 276-282.

42. Ward CD, Duvoisin RC, Ince SE. Parkinson's disease in 65 pairs of twins and in a set of quadruplets. Neurology 1983; 33: 815824.

43. Marsden CD. Parkinson's disease in twins. J Neurol Neurosurg Psychiatry 1987; 50: 105-106.

44. Marttila RJ, Kaprio J, Koskenvuo M, Rinne UK. Parkinson's disease in nationwide twin cohort. Neurology 1988; 38: 1217-1219.

45. Johnson WG, Hodge SE, Duvoisin R. Twin studies and the genetics of Parkinson's disease - a reappraisal. $I n$ : Movement Disorders. Sth ed. 1990: 187-194.

46. Hertzman C, Wiens M, Bowering D. Parkinson's disease: a casecontrol study of occupational and environmental risk factors. Am J Industrial Med 1990; 17: 349-355.

47. Kurtzke JF, Goldberg ID. Parkinsonism death rates by race, sex and geography. Neurology 1988; 38: 1558-1561.

48. Ludin SM, Ludin HP. Is Parkinson's disease of early onset a separate disease entity? J Neurol 1989; 236: 203-207.

49. Rajput AH, Uitti RJ, Stern W, et al. Early onset Parkinson's disease in Saskatchewan. Can J Neurol Sci 1986; 13: 312-316.

50. Tanner CM, Chen B, Wang W, et al. Environmental factors in the etiology of Parkinson's disease. Can J Neurol Sci 1987; 14: 419. 423.

51. Koller W, Vetere-Overfield B, Gray C, et al. Environmental risk factors in Parkinson's disease. Neurology 1990; 40: 1218-1221.

52. Calne S, Schoenberg B, Martin W, et al. Familial Parkinson's disease: possible role of environmental factors. Can J Neurol Sci 1987; 14: 303-305.
53. Langston JW. MPTP-induced parkinsonism: how good a model is it? In: Fahn S, et al., eds. Recent Developments in Parkinson's Disease. New York: Raven Press, 1986: 119-126.

54. Forno L, Langston W, Delanney L. Locus ceruleus lesions and eosinophilic inclusions in MPTP-treated monkeys. Ann Neurol 1986; 20: 449-455.

55. Rajput $\mathrm{AH}$, Uitti RJ, Stern W, et al. Geography, drinking water chemistry, pesticides and herbicides and the etiology of Parkinson's disease. Can J Neurol Sci 1987; 14: 414-418.

56. Calne DB, Lees AJ. Late progression of post-encephalitic Parkinson's syndrome. Can J Neurol Sci 1988; 15: 135-138.

57. The Parkinson Study Group. Effect of Deprenyl on the progression of disability in early Parkinson's disease. N Engl J Med 1989; 321: 1364-1371.

58. The Parkinson Study Group. Datatop: a multicenter controlled clinical trial in early Parkinson's disease. Arch Neurol 1989; 46: 1052-1060.

59. Eldridge R, Ince SE. The low concordance rate for Parkinson's disease in Iwins: a possible explanation. Neurology 1984; 34: 13541356.

60. Mattock C, Marmot M, Stern G. Could Parkinson's disease follow intra-uterine influenza - a speculative hypothesis. J Neurol Neurosurg Psychiatry 1988; 51: 753-756.

61. Ebmeier KP, Mutch WJ, Calder SA. Does idiopathic parkinsonism in Aberdeen follow intra-uterine influenza? J Neurol Neurosurg Psychiatry 1989; 52: 911-913.

62. Rajput AH, Offord KP, Beard CM. A case control study of smoking habits, dementia and other illnesses in idiopathic Parkinson's disease. Neurology 1987; 37: 226-232.

63. Mindham RHS, Ahmed SWA, Clough CG. A controlled study of dementia in Parkinson's disease. J Neurol Neurosurg Psychiatry 1982; 45: 969-974.

64. Mayeux R, Stern Y, Rosenstein R, et al. An estimate of the prevalence of dementia in idiopathic Parkinson's disease. Arch Neurol 1988; 45: 260-262. 